\title{
Los abordajes periodísticos de las problemáticas de los pueblos indígenas en los medios escritos nacionales
}

\section{Journalistic approaches to the problems of indigenous groups in Costa Rica's written media}

\author{
Óscar Ureña García \\ Universidad Federada San Judas Tadeo, Costa Rica \\ cperiodismo@usanjudas.ac.cr
}

\begin{abstract}
Resumen
La prensa costarricense aborda, desde hace muchos años, las problemáticas indígenas de una manera distorsionada. Asume una visión que excluye las problemáticas de los pueblos indígenas de Costa Rica. Cuando las abordan, centran el protagonismo en los no indígenas. Este trabajo muestra y analiza esa mirada distorsionada que se crea a partir de los abordajes periodísticos en los medios escritos nacionales, impresos y digitales, de mayor alcance en el país.

Palabras claves: abordaje periodístico, pueblos indígenas, medios de comunicación, Costa Rica

Abstract

The Costa Rican press has for many years addressed indigenous issues in a distorted way. They assume a vision as if the Costa Rican natives were not part of the country and their realities did not exist and, when approached, they focus the protagonism on the non-indigenous. This paper clearly shows and analyzes that distorted view that is created from the journalistic approaches in the national printed and digital media of greater reach in Costa Rica.
\end{abstract}

Keywords: journalistic approach, indigenous people, mass media, Costa Rica 


\section{Introducción}

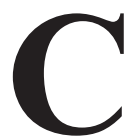
osta Rica es un país multicultural y multilingüe, así lo estipula el artículo 1 de la Constitución Politi$c a$, según la reforma que se realizó el 24 de agosto de 2015. No obstante, los abordajes que realizan los medios de comunicación escritos de mayor alcance, tanto impresos como digitales, no reflejan esto en sus publicaciones. Y, cuando los abordan, centran el protagonismo en los no indígenas, creando así la imagen de que los costarricenses pertenecientes a los pueblos autóctonos son damnificados y necesitados.

Aunque en los últimos años las formas de representación simbólica de los pueblos indígenas han sido una preocupación constante y objeto de estudio en las universidades latinoamericanas, los medios de comunicación escritos y digitales no reflejan, salvo excepciones, la multiculturalidad de nuestro país y las problemáticas sociales que enfrentan los diferentes pueblos aborígenes.

De ahí la importancia de realizar una investigación que analice cómo abordan estos medios de comunicación la realidad social de los pueblos indígenas costarricenses, con el fin de determinar cuánta relevancia tienen sus problemáticas, en cantidad de notas, y mostrar cómo se crea una imagen pasiva y damnificada de ellos. El propósito de este trabajo es identificar la cantidad de notas que les dedican los principales medios escritos, desde setiembre de 2016 hasta setiembre de 2017. Además, de manera complementaria, se realizar un estudio comparativo entre las diferentes notas periodísticas con el fin de establecer posibles similitudes entre ellas para determinar los patrones que rigen los abordajes de los pueblos aborígenes en la prensa escrita nacional.

Analizamos notas publicadas por los medios escritos de mayor circulación en el país: La Nación, Diario Extra, La República y $C R H o y$, en su edición digital, ya que son las que más perduran en el tiempo, tanto en su repositorio digital, como en las redes sociales.

Este artículo forma parte de un proceso investigativo más amplio que está realizando el Departamento de Investigación de la Facultad de Periodismo de la Universidad Federada San Judas Tadeo, con el objetivo de analizar el impacto que tienen en la sociedad, los abordajes que realizan los medios de comunicación masivos, principalmente en las problemáticas de las minorías.

\section{Realidad de los pueblos indígenas costarricenses}

Como explica el estudioso de las lenguas indígenas, Guillermo González Campos en su libro Las miradas con que vemos (2010), describir la realidad social de los pueblos autóctonos de Costa Rica no es una tarea fácil, principalmente porque cada etnia debería ser analizada por separado para no caer en generalizaciones. Por tal razón, nos detendremos en algunos aspectos generales de la situación actual de los diferentes grupos costarricenses que, lamentablemente, no son alentadores.

Existen ocho etnias que habitan nuestro país: bribri, cabécar, boruca, térraba, 
ngäbe, guatuso, chorotega y huetar. Según el último censo (Solano Salazar, 2004), la suma de todos estos pueblos es apenas el $1,7 \%$ de los habitantes de Costa Rica.

Los bribris y los cabécares son las etnias que poseen más habitantes: juntas constituyen el $64 \%$ de la población total indígena. Además, sus lenguas son las que mejor se conservan. Eso no significa que se encuentran en un estado idóneo. Por ejemplo, la variante sureña del cabécar, hablada principalmente en Ujarrás, muestra claros signos de deterioro, como advierte González Campos (2010). Sin embargo, aún conservan rasgos importantes de su lengua y su cultura.

Luego de estos dos pueblos talamanqueños, siguen los borucas que representan el 12\% de la población indígena nacional. Esta etnia se ubica principalmente en la zona sur del país, en el cantón de Buenos Aires de la provincia de Puntarenas. Por desgracia, los borucas han perdido muchos rasgos de su lengua y, por ende, de su cultura. Por ejemplo, la última hablante del idioma murió en el año 2003 y ahora solo sobreviven algunos semihablantes. Con respecto a sus creencias religiosas, la mayoría practica el catolicismo y solo mantienen algunas leyendas orales propias. Su actividad tradicional más conocida y más estudiada es el baile de los diablitos, en el que representan su lucha contra los españoles en la conquista. Esta actividad se ha convertido en los últimos años en una fuente de ingresos gracias al interés turístico, lo cual ha generado cierta discusión entre los borucas que apoyan la explotación y los que consideran que con esto se pierde parte de su cultura.
La realidad social, cultural y de la lengua de los térrabas no es diferente. Su dialecto está extinto desde el principio del nuevo milenio, su último hablante murió en 2003. Originalmente, este pueblo viene de la zona de Bocas del Toro en Panamá. Actualmente se están realizando esfuerzos por recuperar el idioma con los habitantes de esta etnia en el país vecino, donde conservan aún su lengua e importantes rasgos culturales.

Los ngäbe, por su parte, constituyen aproximadamente el 8,2\% de la población indígena costarricense, no obstante, el número es fluctuante debido a que cerca de 15 mil viven entre Panamá y Costa Rica, dependiendo de la época de recolección de café y otras cosechas. La mayoría de su población habita en Panamá con más de 150 mil que mantienen su idioma, su cultura y gozan de una importante inclusión social, educativa y laboral. Por ejemplo, tienen representación en la Asamblea Legislativa de Panamá. Sin embargo, la realidad social de su contraparte costarricense es muy lejana: están sufriendo la pérdida de sus tierras, el deterioro de su lengua y tradiciones.

Los guatusos representan el $3,4 \%$ de la población, poco más de mil personas que habitan la zona norte del país. Su lengua se mantiene activa; sin embargo, está en gran riesgo, pues posee muy pocos hablantes. Las demás etnias: huetares y chorotegas tienen extintos sus dialectos desde hace cientos de años. Por su parte, no mantienen rasgos o tradiciones culturales más allá de sus métodos de subsistencia y artesanía.

Este breve recorrido ha detallado la realidad de la lengua y rasgos culturales de cada etnia; sin embargo, también viven 
una gran cantidad de problemas sociales. Según datos del Estado de la Nación de 2011, el porcentaje de analfabetismo de la población indígena en general es de 7,7 mientras que el de la población no indígena es de un 2,2. Por su parte, el porcentaje de personas indígenas con acceso a electricidad es de 79,7 en comparación con el 98,9. Lo mismo sucede con el acceso al agua potable: 66,5 en el caso de indígenas y 93,2 en los no indígenas.

Tanya Chapuisat, representante de UNICEF en Costa Rica, detalló que "el Comité de los Derechos del Niño, en su informe del 2011, refiriéndose a la salud indicó la elevada tasa de mortalidad infantil que casi triplica la media nacional y los porcentajes de pobreza que abarcan entre el $85 \%$ y $95 \%$ de los habitantes indígenas" (UNICEF, 2012).

Otra problemática que estos grupos experimentan es el robo de sus tierras. En 2015, la Comisión Interamericana de Derechos Humanos solicitó al país un informe sobre las medidas de protección a los indígenas de la zona de Salitre, luego de una gran crisis entre 2012 y 2013 en la que personas no indígenas se enfrentaron violentamente por problemas de usurpación de tierras. En 2015, la Comisión solicitó medidas cautelares contra el Estado costarricense en pro de los bribris y térrabas en Salitre, detalló La Nación el 5 de mayo de 2015, en su nota titulada: "Estado dará cuentas sobre protección a los indígenas". Aunque existen decretos presidenciales y la Ley Indígena de 1977 que protegen sus derechos de tierra, que califican de "exclusivas, inalienables y no transferibles", la realidad es que son usurpadas. Según datos del
Ministerio de Planificación de Costa Rica, de las 9350 hectáreas que constituyen la reserva en Buenos Aires de Puntarenas, el $88 \%$ no está en posesión de los indígenas.

De los 24 territorios que están protegidos por ley, se estima que el $40 \%$ está en manos de personas no indígenas, según datos de la Defensoría de los Habitantes de Costa Rica y el Programa de las Naciones Unidas para el Desarrollo (PNUD) en 2014. Ese mismo año, la coordinadora del PNUD en Costa Rica, Yoriko Yasukawa, declaró: "No se puede avanzar en materia de derechos humanos, si un derecho tan básico como la tierra no está garantizado. Esas tierras son exclusivas de los indígenas" (La Nación, 2014).

Por otra parte, una problemática significativa es la educación. El analfabetismo y la deserción escolar son frecuentes. Además, uno de los problemas más grandes es que se les enseña solo en español y la educación que reciben está determinada por los currículos que se establecen para los no indígenas.

En el informe Derecho a la salud y educación indígena en Costa Rica, realizado por Unicef en 2016, se especifica que: "El servicio educativo que brinda Costa Rica a sus pueblos indígenas, forma parte del Sistema Educativo Nacional; por tanto, no puede desvincularse de los fundamentos, los objetivos ni de los fines que rigen y persigue la Educación Nacional. Así, la Educación Indígena no deja de estar determinada y delineada por las políticas educativas y curriculares establecidas en el nivel nacional, las cuales se relacionan con planes y programas de estudio, enfoque curricular, promoción, 
evaluación, material didáctico, administración y formación docente, entre otros" (Unicef, 2016).

Como podemos ver, las realidades sociales de los pueblos autóctonos son diversas. No obstante, sufren problemáticas en común, principalmente de abandono y exclusión social que contribuyen al deterioro de sus costumbres, rasgos culturales y lengua.

\section{Deontología en el tratamiento informativo de las problemáticas indígenas}

Generalmente, como se mostrará más adelante en este análisis, los medios estudiados en este trabajo abordan poco los temas, problemáticas y realidades de los pueblos indígenas que se han mencionado anteriormente. Cuando lo hacen, en general, los abordan desde una lejanía y con el foco de la nota en lo no indígena. Como bien resaltan Esquivel y González (2010), esto se debe no tanto a una voluntad, sino más a una forma inconsciente, por el paradigma dominante que muchos periodistas y medios de comunicación reproducen. Aunque también existen algunos abordajes que, claramente, han sido premeditados, en los que los colocan como damnificados $o$, en otro caso, centran el protagonismo en los no indígenas. No obstante, sea por omisión o no, la realidad es que el abordaje, en su mayoría, es escaso y cuando se dedica algún espacio, se muestra una realidad ajena, lejana o arquetípica.

Tal y como lo propuso Michel Foucault en su Arqueología del saber (1991), los conocimientos son construidos socialmente $\mathrm{y}$ reproducidos por efectos del poder en términos de verdad. Esto quiere decir que hay fuerzas de poder que normalizan lo que está bien o mal a partir de un conocimiento. Y los pueblos indígenas no escapan de este enfoque, ni tampoco los medios de comunicación escritos de Costa Rica. Estas ideas aceptadas pueden crear imágenes favorables o, por el contrario, imágenes desfavorables contra las que todo comunicador y, en este caso, los periodistas, deben luchar.

Precisamente, por esa razón, es importante tener en cuenta la deontología a la hora de abordar o tratar la información que se genera sobre los indígenas costarricenses. En primer lugar, se debe entender, como lo plantea el Informe MacBride de la Unesco Un solo mundo, voces múltiples, información y comunicación en nuestro tiempo, que la comunicación tiene el deber de que, en el futuro, exista más de una historia de la humanidad. No solo la historia hegemónica, sino las diferentes historias que muestren la pluralidad.

Para esto es vital una comunicación que respete los derechos humanos y un ordenamiento social y de la comunicación más justo, en el entendimiento y la igualdad de los diferentes pueblos, además de eliminar los desequilibrios y disparidades en la comunicación y la información, que han estado siempre centrados en los grupos hegemónicos. "Los desequilibrios de los sistemas nacionales de información y comunicación, son tan perturbadores e inaceptables como las disparidades sociales, económicas, culturales y tecnológicas, tanto nacionales como internacionales" (Unesco, 1980, pág. 209). 
Además, este informe de la Unesco promueve que las prácticas éticas de la comunicación deben asegurar que los diferentes grupos puedan hacerse oír. "Los medios masivos deben contribuir a la promoción de la causa justa de los pueblos que luchan por la libertad, independencia y por su derecho a vivir en paz e igualdad" (Unesco, 1980, p. 234).

Por otra parte, es vital comprender lo que plantea el Manual de estilo sobre minorías étnicas del Colegio de Periodistas de Cataluña (1996): "Es necesario evitar las generalidades, los maniqueísmos y la simplificación de las informaciones". Y agrega que las minorías son tan poco homogéneas como las mayorías. Un elemento revelador que no se toma en cuenta a la hora de abordar las problemáticas indígenas: no son todos iguales.

Así mismo, una práctica éticamente no funcional se da cuando se ubica a los indígenas en un papel pasivo. Como reflexiona Teun A. Van Dijk en su libro Discurso y Poder, con respecto al abordaje que realizan los medios de comunicación sobre las minorías:

Casi no se cubren o se resta importancia a las cuestiones y los temas que les tocan directamente, tales como la discriminación, el racismo, la brutalidad policial, la escasez de empleos, las condiciones miserables de trabajo, los fracasos educativos de las minorías, $\mathrm{y}$ muchos otros, y esto sucede cuando la responsabilidad de la situación recae en las élites blancas. Por otro lado, habitualmente, se da una amplia cobertura de las acciones de las élites blancas definidas como "positivas", para las minorías. (Van Dijk, 2011, p.134)
Uno de las prácticas más comunes en los principales medios escritos es centrar el foco de las notas en las élites blancas, como las llama Van Dijk. Además, se abordan las problemáticas sociales que ubican a los indígenas en el papel de damnificados y se exalta enormemente la labor de los no indígenas para ayudarlos. En muchos casos, como veremos en el análisis de las notas, se pasa por alto la debida contextualización de por qué los indígenas sufren esa problemática.

La influencia que los medios de comunicación tienen en la visión de que la sociedad construye sobre la realidad, obliga a que los comunicadores asuman un compromiso más firme en la tarea de mostrar las realidades desde una visión inclusiva y pluricultural. Se centra el abordaje en los indígenas como sujetos y no como predicados.

Lamentablemente, en Costa Rica no existe un manual semejante al del Colegio de Periodistas de Cataluña o alguna referencia al abordaje periodístico de las minorías en el Código de Ética del Colegio de Periodistas de Costa Rica. No obstante, como se mencionó en el informe MacBride, la comunicación y el periodismo tienen que respetar la pluralidad de voces y de pueblos, además de luchar contra los desequilibrios informativos.

De esa manera, podremos ver un cambio positivo hacía más y mejores abordajes periodísticos sobre los temas, realidades y problemáticas de los diferentes pueblos indígenas costarricenses, y tener un criterio de prácticas éticamente funcionales en los medios de comunicación. 


\section{La realidad en los medios de comunica- ción costarricenses}

Lo que no está en los medios de comunicación no existe. Como reflexionaba Norbert Bilbeney en su libro Ética del periodismo (2012), la imagen que las personas crean sobre el mundo es la que construyen a partir de lo que les muestra la prensa. En otras palabras, las personas ven la realidad a partir de lo que se refleja en los medios de comunicación. Y esto es lo que pasa con las problemáticas de los pueblos indígenas costarricenses, pues, al no mostrarse, parece que no existen. Esto puede demostrarse al comparar la cantidad de notas periodísticas que se producen en los medios de comunicación analizados, sobre las realidades sociales de los costarricenses no indígenas, contra las notas de temas de costarricenses indígenas. La realidad es abrumadora.

Para este análisis se realizó una recopilación de las notas desde setiembre de 2016, hasta setiembre de 2017. El resultado es un total de 90 noticias que abordan los temas y problemáticas indígenas, con la siguiente distribución:

- La Nación: 23

- Diario Extra: 19

- La República: 17

- CR Hoy: 31

Llama la atención que, en 365 días, se hayan publicado tan solo 90 noticias en todos los medios mencionados. Con una producción de poco más de 40 mil notas en ese lapso, tan solo 90 se centraron en la realidad de los pueblos indígenas costarricenses. Eso significa que representan el $0.2 \%$ de lo que se publica, en los principales medios escritos costarricenses, en un año. Una prueba de lo excluidos que están estos pueblos en los medios de comunicación y, por lo tanto, en el imaginario colectivo.

De ahí la relevancia de realizar el análisis de esas notas para determinar si existe un patrón de abordaje de problemáticas que cumpla o no con la propuesta de prácticas éticamente funcionales, antes mencionadas.

\section{La Nación}

A continuación, analizaremos las notas publicadas por el diario La Nación, para identificar si diferencian la pluralidad de los pueblos aborígenes y brindan un papel activo en el abordaje del tema.

De las 23 notas publicadas en ese periodo por el diario La Nación, ocho (un 34,8\%

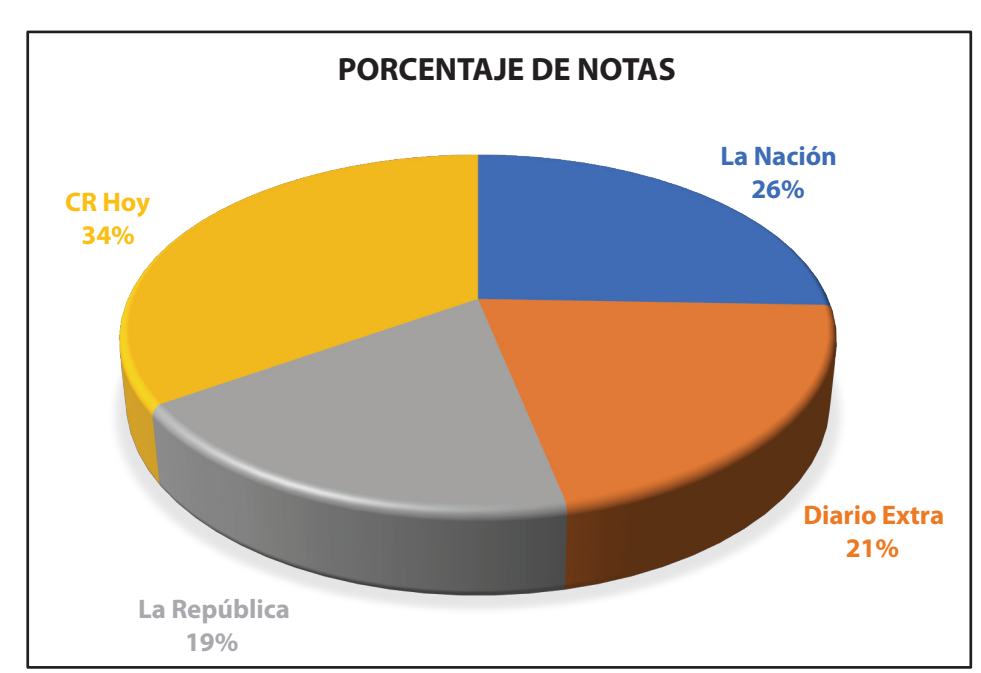


del total) son sobre temas que no afectan directamente a los pueblos autóctonos. Por ejemplo, la nota que mejor lo muestra es la publicada el 19 de abril de 2017, titulada "Universidad Nacional celebró diversidad cultural en el Día del Aborigen". La nota destaca el evento realizado por la Universidad Nacional, en la que se les entregó un reconocimiento a los líderes comunales indígenas y se desarrolló una feria en la que vendieron sus artesanías.

En este caso, no se muestra ninguna problemática ni realidad de los pueblos indígenas. Además, desde la titulación, el enfoque está centrado en el ente universitario y no en los pueblos indígenas. Una constante de la mayoría de medios de comunicación, que centran el foco en los no indígenas, antes que en la participación activa o en la realidad indígena, una prueba de que los abordajes se centran, como lo recalcaba Van Dijk (2008), en exaltar el papel del poder hegemónico y excluir a las minorías.

Por su parte, esta nota no toma en cuenta la diversidad y diferencias de los pueblos costarricenses. Sino que generaliza el término indígena sin especificar de qué etnia son los que vendían artesanías, solo especifica la zona de donde vienen. Simplificar y unificar una realidad tan diversa es un error que alimenta la mirada excluyente y de lejanía. En esta nota lo podemos ver a continuación: "Rafael Ángel Sánchez, indígena de Quitirrisí, llegó a exponer y vender su alfarería. "Estoy mostrando las artes indígenas que tenemos nosotros en nuestra tierra. Me gusta mucho venir aquí porque uno conoce gente y comparte. El año pasado también vine", dijo" (Rodríguez, 2017).
Sin duda alguna, este tipo de notas periodísticas no contribuye ni suma para mostrar la problemática que tienen los diferentes pueblos indígenas costarricenses. Además, se reduce una población tan variada y compleja a algo simple y monolítico. Esto genera que las problemáticas se reduzcan a hechos ambiguos, como las actividades realizadas por entes no indígenas.

De las 23 notas realizadas por este medio, ocho tienen un enfoque similar a la nota recién mencionada. En las que no abordan ninguna problemática y los posicionan en un papel de "creadores de artesanía". Incluso, en algunas notas ni siquiera los mencionan desde la titulación como se aprecia en estas publicaciones: "Exposición 'Somos todos Costa Rica' se exhibe a las afueras del Estadio Nacional", publicada el 4 de julio y en: "En el FIA: Parque Nacional luce 69 puestos de artesanía de todo Costa Rica", publicada el 30 de junio.

Además de este tipo de notas, cinco del total publicadas por La Nación (21,7\%) se centraron en un tema coyuntural: el encuentro realizado en mayo de 2017 para discutir los mecanismos de consulta a los pueblos indígenas. Un tema relevante y al cual La Nación le dio un seguimiento especial con cinco notas. Se debe destacar que fue el único medio que realizó una cobertura de seguimiento tan grande.

La primera publicación sobre este tema titulada "Indígenas de Costa Rica discutirán propuesta de mecanismo de consulta en mayo", se publicó el 17 de marzo de 2017, dos meses antes del evento, en la que se informaba que el evento se realizaría en mayo y los objetivos que se pretendían. 
Lo que más llama la atención de esta nota es que el foco se centra en los pueblos indígenas y los ubica en un papel activo para resolver una problemática que los afecta directamente: un mecanismo satisfactorio para consultar a los diferentes pueblos indígenas sobre cualquier iniciativa que se quiera desarrollar en las tierras que habitan, tanto en infraestructura, políticas públicas, entre otros temas.

Esto sucede con las restantes cuatro notas sobre el tema. No obstante, llama la atención que este medio realiza esta cobertura debido a un tema coyuntural como es el encuentro ya mencionado. Sin embargo, fuera de este evento, los abordajes y las miradas que crean las notas siguen con la línea mencionada al principio de este análisis. Aunque es un punto positivo que estas cinco notas hayan tenido un abordaje destacado de la realidad de los pueblos indígenas y que se mostrara en un papel activo a los indígenas, es una excepción coyuntural que solo representa el $21 \%$ de las notas publicadas por este medio.

Por otra parte, el 34,8\% de las notas, trata temas que afectan directamente a los pueblos autóctonos. Sin embargo, aunque se abordan problemáticas que podrían ser relevantes, los ubican en un papel pasivo, en el que ellos se ven beneficiados por los no indígenas.

Esto se puede apreciar con mucha claridad en la nota publicada el 21 de mayo, titulada: "Indígenas de Limón serán operados de la vista en junio", en la que se informa sobre cómo la Caja Costarricense del Seguro Social detectó por medio de un tamizaje, que más de treinta indígenas de la zona Atlántica tenían problemas visuales y les realizarían la operación para que su salud visual mejore sustancialmente. Esta noticia es verdaderamente significativa para la población indígena de la zona; sin embargo, no se detalla de cuál etnia son los indígenas que serán beneficiados, sino que se aborda desde una generalización. Además, el centro de la nota está enfocado en los esfuerzos de la Caja Costarricense del Seguro Social y no en la problemática de la salud visual que viven como las causas y las consecuencias de esta problemática. Se ubica a los indígenas en un papel pasivo, damnificados que necesitan la ayuda de los no blancos para resolver sus problemas.

Esto también se evidencia en la nota publicada el 4 de mayo, titulada: "Mujeres indígenas de Copey aprenden a jugar fútbol y con él, sus derechos". En esta que se informa sobre los torneos de fútbol que realiza la organización Seprojoven y cómo, en conjunto con otras instituciones, las indígenas ngäbe de Copey de San Vito de Coto Brus aprenden sus derechos jugando fútbol. No obstante, de nuevo, el foco de esta nota está dirigido a la organización que realiza los eventos e, incluso, se dedica el último párrafo para brindar la información sobre cómo se puede ayudar y dar donaciones a esta organización. El enfoque de la nota no está en la realidad de los derechos de las mujeres ngäbe. Y esto se evidencia porque no se realiza una contextualización de cuál es la realidad de las mujeres y sus derechos, simplemente se menciona que por medio de los torneos de fútbol que realiza esta organización, las mujeres conocen sus derechos. A pesar de que se aborda específicamente una cultura y se los identifica como tal, en esta nota se los pone como damnificados. El 
enfoque está en la organización que ayuda a las mujeres a conocer sus derechos y no verdaderamente por qué las mujeres indígenas sufren la violación de sus derechos.

Por último, otras dos notas publicadas por La Nación, que representan el 8,7\%, muestran una mirada heroica de algunos indígenas. Informan sobre la historia de hombres y mujeres que han aportado a sus pueblos. Sin embargo, se queda corta en relación con las problemáticas indígenas y, en ocasiones, parece ser una mirada muy superficial sobre la situación de los pueblos autóctonos.

Esto se puede apreciar en la nota "Mirna, la médica ngäbe, sueña con atender indígenas", publicada el 30 de junio, en la que se informa que Mirna, una médica ngäbe que se graduó en Cuba, logró equiparar su título y ser admitida en el Colegio de Médicos para ejercer en Costa Rica.

La otra nota fue publicada el 12 de julio, titulada "Miguel, el cabécar que dio su vida por la salud", que informa la muerte de Miguel Murcia, un indígena cabécar que murió arrastrado por un río cuando intentaba cruzarlo para llevar medicamentos a la zona de Chirripó. La nota busca destacar la labor de Miguel como un Asistente Técnico de Atención Primaria (Atap) en la zona y su aporte al pueblo cabécar.

A pesar de que pueden ser notas que no profundicen en la realidad y en la problemática indígena de nuestro país, hay que destacar que, en ambas, La Nación le da un papel activo a los indígenas y diferencia su etnia, sin generalizaciones. No obstante, son solo dos notas de las 23 que se publicaron en este medio.
Podemos apreciar que, con la excepción de estas dos notas y una coyuntura temática, como lo fue el caso del encuentro para discutir los mecanismos de consulta, los abordajes que realiza el diario La Nación suelen ser enfocados en lo no indígena; además, se los ubica en un papel pasivo, posicionándolos como personas que necesitan ayuda para subsistir, tener salud, trabajo y calidad de vida. Por otra parte, la mayoría de notas de este medio, generalizan a los diferentes pueblos indígenas de nuestro país.

\section{Diario Extra}

Diario Extra presume ser el medio de comunicación escrito de más venta en Costa Rica. Tiene, además, una característica interesante y es que se considera el diario del pueblo. Esto llama la atención porque, a pesar de tener fama de ser un medio sensacionalista, en muchas de las notas que publicaron durante el periodo de análisis, se apreciaron prácticas éticamente funcionales en el abordaje de las problemáticas y realidades de los pueblos indígenas costarricenses.

De las 19 notas publicadas por Diario Extra, llama la atención que, en seis de ellas, un $31,6 \%$ del total de sus publicaciones sobre estos temas, los indígenas tienen, desde el titular, un papel activo.

Una de las notas que muestra esto con más claridad es "Indígenas se manifestarán en Fiscalía General", que detalla la manifestación que realizaron los indígenas ante la Fiscalía, debido a los procesos legales que se abrieron contra un grupo de ellos, acusados del delito de usurpación de territorio 
indígena, sin verificarse y tomar en cuenta que las personas acusadas eran indígenas.

Llama la atención que, en el abordaje, tanto en el título como en el cuerpo de la nota, los indígenas tienen un papel activo y se los muestra defendiendo sus derechos. Sin intermediarios. Además, el centro de la nota no está en los no indígenas, más bien se centra en una problemática que verdaderamente los afecta y visibiliza el racismo y discriminación que sufren en muchas ocasiones. Esta noticia generó otra nota de seguimiento en la que el mismo periodista cubrió la manifestación. Es un texto más breve, pero de la misma manera, cumple con los puntos analizados en la nota previa.

Por su parte, se destaca la nota que abordó la respuesta del Fiscal General sobre la manifestación que realizaron los indígenas de la zona sur, además de la reunión que mantuvo con los representantes indígenas. En esta nota, se les da un papel activo a los representantes indígenas se citan como fuente de manera directa dentro de la nota se resalta la respuesta del Fiscal de que se le haría justicia restaurativa a los indígenas procesados. Sin duda, apreciamos prácticas éticamente funcionales al identificar debidamente la etnia, contextualizar en la problemática y ubicar a los afectados en un papel activo, sin destacar a los no indígenas.

Además, dentro de estas notas sobresale la titulada: "Indígenas ayudan a damnificados tras el paso del huracán Otto", publicada el 1 de diciembre de 2016, en la que se destaca la labor de los indígenas de la zona de Talamanca, que recolectaron comida no perecedera y ropa para las personas damnificadas por el huracán, que afectó gravemente las zonas de Upala, Bagaces, entre otras, en noviembre de ese año. Dentro de este análisis, Diario Extra fue el único medio que abordó este tema en el que se destaca el papel activo de los indígenas del cantón de Talamanca. Esta nota sobresale porque en ningún otro medio se muestra un protagonismo de algún pueblo indígena con esta magnitud.

Por otra parte, del total de notas publicadas, diez de ellas, un 52,6\%, abordan temas que verdaderamente impactan en los pueblos aborígenes. Aunque lo hacen desde una perspectiva de "los otros", rompiendo la línea de las notas anteriormente analizadas.

Una nota que ejemplifica esto es la publicada el 4 de noviembre de 2016, titulada "Operación aérea busca salvar 200 indígenas en Piedra Mesa, Talamanca", en la que destaca la labor de la Caja Costarricense del Seguro Social, en conjunto con el Comando Sur de Estados Unidos y la Fuerza Aérea de ese país, para hacer llegar ayuda médica a esa región de difícil acceso.

En este caso, es un tema que verdaderamente afecta a los indígenas de la zona. No obstante, se muestra una imagen de indígenas damnificados que necesitan de ayuda de los no indígenas para tener los servicios básicos de salud, como vacunas y alimentos. Además, no se especifica cuál es el grupo indígenas que es atendido. Solo se menciona la región.

Otras notas como la titulada "Estudiantes de medicina atenderán indígenas en Tsipiri a 1 hora del centro de Turrialba", también es un ejemplo de las que abordan temas 
importantes, pero siempre se los ubica en un papel pasivo y no se explica su contexto ni se detalla por qué estos pueblos no tienen una cobertura de salud adecuada. En esta nota se resalta la labor de un grupo de estudiantes de medicina de la Universidad Hispanoamericana.

Por último, tres notas publicadas por Diario Extra, un 15,8\%, se centraron en sucesos ocurridos a indígenas. Una de las notas más ejemplares es la titulada "Balean dos indígenas recuperadores de Cabagra", publicada el 19 de octubre de 2016, en la que detalla que dos indígenas de Cabagra, que eran parte de los grupos que intentaron recuperar sus tierras en la Zona Sur, fueron baleados por los finqueros que presuntamente habían ocupado las tierras indígenas. La nota no detalla los hechos de una manera clara, solo cita que fueron heridos de bala y trasladados al hospital de Pérez Zeledón.

No obstante, dentro de estos textos periodísticos se destaca una nota elaborada por Diario Extra publicada el 16 de julio de 2017, titulada: "Indígenas ticos pagan para entrar a su propio país". Un trabajo de investigación breve que muestra las dificultades que viven a diario los indígenas de Punta Burica, que se trasladan a Panamá para trabajar o visitar a su familia, pero son detenidos a la hora de regresar.

En esta nota se informa sobre la ausencia de acción por parte del gobierno y el incumplimiento, por parte de Costa Rica y Panamá, de los convenios binacionales que existen para que los indígenas de la zona puedan ir y venir libremente a los pueblos cercanos de Panamá.
Podemos apreciar que Diario Extra es un medio que aborda las problemáticas de los pueblos indígenas desde una perspectiva más éticamente correcta. En varias notas se los muestra desde un papel activo; además, se detallan problemáticas que viven y cómo muchas veces los acuerdos u obligaciones gubernamentales no se cumplen como debería ser. No obstante, no escapan de mostrar en ocasiones a los indígenas desde un papel pasivo y dependiente de la ayuda de los no indígenas.

\section{La República}

La República es un diario con mucha trayectoria. En los últimos años ha apostado por un contenido más político y económico. No obstante, en su versión digital cubre más detenidamente temas sociales. Durante el periodo de análisis, este medio publicó un total de 17 notas que abordan de alguna manera las problemáticas de los pueblos indígenas costarricenses.

De estas notas, un 76,4\%, 13 de ellas, posicionan a los indígenas en un papel pasivo $\mathrm{y}$, en ocasiones, minimizado. El abordaje se centra en la labor de los no indígenas para ayudar a los indígenas. Incluso, en situaciones en las que los indígenas tuvieron un protagonismo, se los excluye o ubica en un papel pasivo.

Esto se demuestra en notas como la publicada el 28 de noviembre de 2016, titulada "INA gradúa a 15 mujeres indígenas en agricultura ecológica", en la que se detalla cómo esta institución educativa impartió un curso de tres meses en el que aprendieron a desarrollar técnicas de cultivos libres de químicos. No obstante, llama la 
atención que desde el título se posiciona al INA con el papel activo y a las indígenas graduadas, en un papel pasivo. El INA tiene el papel de graduar, cuando en realidad quienes se graduaron fueron las indígenas de la zona de Los Chiles y Upala. Además, no se detalla a cuál pueblo indígena pertenecen estas mujeres. Tan solo se mencionan las zonas de donde vienen. Se crea la imagen de que son beneficiadas por este proyecto y no que son agricultoras o pequeñas empresarias.

Otro ejemplo de este tipo de notas se puede apreciar en la publicación del 23 de febrero de 2017, titulada "Minae ayudará a poblaciones indígenas de Talamanca y guardaparques". En esta nota, se detalla que en la gira que realizó el jerarca del Ministerio de Ambiente y Energía por las zonas indígenas bribris y cabécares de Talamanca, se comprometió a brindar ayuda para pavimentar las calles de algunas comunidades y reforzar el cuidado de los bosques.

Aunque es positivo que se pavimenten las calles y se refuerce el cuidado de los bosques, llama la atención que de nuevo se ubica a los indígenas desde un papel pasivo y que necesitan la ayuda de los no indígenas. Por ejemplo, en esta nota, y en muchas otras de las publicadas por este medio, no se contextualiza ni se citan antecedentes o razones del porqué no cuentan con carreteras pavimentadas.

Esto también sucede con la nota publicada el 9 de diciembre de 2016, en la que se detalla la ayuda que realizaron los estudiantes de la Universidad Hispanoamericana en la zona indígena de Turrialba. En este caso se centra todo el protagonismo e, incluso, se exalta el papel de estos estudiantes y su universidad, pero no se detalla por qué razón 800 indígenas de Turrialba no tienen atención médica.

De las 17 notas, tan solo dos les dan a los indígenas un papel más activo, siendo un poco más del $11 \%$ del total de las notas publicadas por este medio. Un ejemplo significativo es la nota titulada "Guías turísticos indígenas abrirán agencia de viajes", que menciona cómo un grupo de indígenas bribris y cabécares podrán abrir su propia agencia de viajes con el objetivo de mostrar el bagaje cultural de la zona y de estas etnias. No obstante, aunque el titular muestra un papel más activo, en la nota se destaca mucho la labor del Instituto Tecnológico y el Instituto Costarricense de Turismo, quienes dieron la capacitación. Aunque sí se posiciona a los indígenas en un papel protagónico.

Otra nota que muestra esto es la publicada el 8 de marzo de 2017, titulada "Mujeres indígenas viajarán a India para realizar estudios en ingeniería solar", en la que se detalla que cuatro mujeres ngäbe viajarían a este país asiático para realizar estudios en ingeniería solar. Desde el título se aprecia cómo el protagonismo está centrado en las mujeres indígenas y no en los entes que intervinieron para que esto fuera posible. Aunque se mencionan en el contenido de la nota, el papel activo lo tienen las mujeres ngäbe que viajarían a India para prepararse y, lo más importante que destaca la nota es regresar para ayudar a sus comunidades con estas capacitaciones que recibirían.

Las otras dos publicaciones que suman el $11.8 \%$, una se centra en decisiones 
administrativas que benefician a los pueblos, publicada el 5 de noviembre de 2016 y se titula "Costumbres indígenas serán tomadas en cuenta en partos en Limón", que detalla la decisión asumida por la Caja Costarricense del Seguro Social de tomar en cuenta las costumbres de las diferentes etnias a la hora de dar a luz, luego de un foro en el que las indígenas ngäbe, bribris y cabécares compartieron sus costumbres sobre el parto. Es una de las notas que destacan la inclusión y la diversidad de nuestro país de manera más clara.

La otra publicación titulada "Estudio afirma que pueblos indígenas de la región siguen en rezago", publicada el 31 de marzo de 2017, detalla los datos de un estudio sobre la realidad social de estos pueblos, refleja el rezago educativo que tienen los indígenas de Latinoamérica. Aunque la publicación muestra datos relevantes, no se detallan las cifras de Costa Rica y se aborda de una manera muy breve los resultados. Sin embargo, es una publicación que muestra una problemática de estos pueblos.

\section{Costa Rica Hoy (CR Hoy)}

El diario Costa Rica Hoy, más conocido como CR Hoy, es un medio completamente digital que tiene pocos años; no obstante, se ha posicionado como un medio escrito con una gran cantidad de lectores. Al ser un medio exclusivamente digital, ha logrado aprovechar las redes sociales para llegar a los lectores. Sin embargo, esa inmediatez, en ocasiones, ha sido criticada por ciertas imprecisiones en sus textos.

De las 31 notas publicadas en el periodo de análisis sobre las problemáticas de los pueblos indígenas costarricenses, llama la atención que 25 de ellas, un $80,6 \%$, posicionan a los indígenas en un papel pasivo $\mathrm{y}$, además, damnificado, que necesita la ayuda constante de los no indígenas. Esto se manifiesta con mayor claridad en la nota publicada el 5 de junio de 2017, titulada "Jornada oftalmológica atendió a indígenas de Talamanca", en la que se detalla la labor realizada por la Caja Costarricense del Seguro Social en la jornada oftalmológica en la región de Talamanca. Sin embargo, llama la atención que se centra en la labor no indígena e, incluso, no se cita a ningún beneficiado como fuente. Todas las citas son de personas no indígenas. A pesar de esto, se debe destacar que sí se detallan las etnias costarricenses que recibieron la atención médica.

Otro ejemplo de esto se aprecia en la nota titulada "Policías cambian rutina y dan ayuda en zonas indígenas", publicada el 7 de setiembre de 2016, en la que se muestra la labor social de un grupo de oficiales de la Policía de Control de Drogas (PCD), que dejaron sus labores por un día para llevar ropa y alimentos a los indígenas de Talamanca en las zonas que han erradicado los sembradíos de marihuana. De nuevo, en este caso, se aprecia el mismo patrón de posicionar a los indígenas en un papel pasivo y damnificado y se exalta la labor de los no indígenas. Por otra parte, las fuentes, no indígenas, detallan las labores de ayuda que realizan. Por último, no se detallan las etnias, solo las zonas donde se realizó la ayuda.

Otra nota que ejemplifica esto es la publicada el 31 de mayo de 2017 que se titula "Lanzan app para servicio de taxis que 
ayudará a indígenas", en la cual se detalla cómo una nueva aplicación para solicitar el servicio de taxis donará sus ganancias para la construcción de un centro indígena en Quitirrisí, para brindar atención médica a los indígenas del cantón de Mora. En esta nota, de nuevo, se centra el protagonismo en los no indígenas que crearon y lanzaron la aplicación y la ayuda que brindarán. Por último, no se cita a ningún indígena como fuente y la nota cierra con un llamado a los taxistas interesados en trabajar con esta aplicación a contactarse con los encargados.

Como lo muestran estas notas, hay un total de 25 que tienen ese abordaje, centrado en el protagonismo de los no indígenas y mostrando una imagen de que los indígenas son personas que necesitan de la ayuda para obtener salud, comida y ropa. Pero en ninguna de estas notas se profundiza o contextualiza las razones de por qué tienen poco acceso a la salud, comida, educación y ropa.

De las seis notas restantes, que representan tan solo el $19,4 \%$, sí se puede apreciar un papel más activo de los indígenas. Una de las notas que muestran esto es la titulada "Mujeres indígenas aprenderán a instalar paneles solares", publicada el 20 de marzo de 2017, en la que se detalla que cinco mujeres indígenas viajarán a la India a recibir capacitación de energía solar para ayudar a sus comunidades. En ella se puede apreciar desde el titular cómo se posiciona a las mujeres indígenas en un papel activo. Además, hay que destacar que se contextualiza en las problemáticas de acceso a electricidad cuando se menciona que: "Actualmente en Costa Rica existen aún 4 mil familias que no tienen energía eléctrica. Con este curso se estima que cada una de estas mujeres podrá instalar cerca de 50 paneles en viviendas" (Villalobos, 2017).

Otra nota en la que se aprecia este papel activo de los indígenas es la publicada el 15 de octubre de 2016, titulada "Indígenas bribri tendrán su propia agencia de turismo". Podemos apreciar nuevamente cómo desde el título se posiciona a los indígenas en un papel activo. También, desde el titular se detalla la etnia de estos indígenas costarricenses que iniciarán la función de su agencia de turismo. Además, el cuerpo de la nota evidencia un papel protagónico de estos indígenas con la frase: "Los primeros guías turísticos indígenas bribri, abrirán próximamente su propia agencia turística" (Ugarte, 2016).

Podemos apreciar cómo el principal abordaje de las problemáticas de los pueblos indígenas costarricenses en el diario $C R$ Hoy es, en su mayoría, de notas que posicionan a los indígenas como personas damnificadas que necesitan la ayuda de los no indígenas. Además, en pocas ocasiones los indígenas tienen el papel activo y no suelen ser las principales fuentes en las notas que abordan sus problemáticas.

\section{Conclusiones}

A partir de esta visión, podremos ver cómo el abordaje periodístico de la mayoría de notas realizadas en los medios de comunicación escritos costarricenses no cumple con esta propuesta de prácticas éticamente funcionales, lo cual contribuye a generalizaciones o a reforzar prejuicios que no coinciden con la realidad. 
Con la excepción de las cinco notas coyunturales sobre el encuentro de los pueblos indígenas con el gobierno, los abordajes realizados por el diario La Nación destacan la labor de los no indígena y ubica a los indígenas en un papel pasivo, posicionándolos como personas que necesitan ayuda para subsistir, tener salud, trabajo y calidad de vida.

Por su parte, los abordajes en la mayoría de notas publicadas por Diario Extra se aprecian las problemáticas de los pueblos indígenas desde una perspectiva más éticamente correcta. En varias notas se los muestra desde un papel activo; además, se detallan problemáticas que ellos viven. Sin embargo, este medio no escapa de mostrar a los indígenas desde un papel pasivo y que dependen de la ayuda de los no indígenas.

Los abordajes realizados por La República no se diferencian de los demás. Incluso, en este medio más del $76 \%$ del total de notas publicadas enfocaban el protagonismo en los no indígenas. Además, no se trataba a los indígenas de una manera general, sin detallar sus pueblos. A pesar de tener cuatro notas que de cierta manera cumplen con las prácticas éticamente funcionales, el peso mayor de sus publicaciones se centra en las problemáticas desde el protagonismo de los no indígenas.

El medio digital CR Hoy, por su parte, posee en su mayoría abordajes con prácticas éticamente no funcionales. Más del $80 \%$ de sus notas abordan las problemáticas indígenas destacando, así, la labor de los no indígenas y creando la imagen de que los indígenas costarricenses necesitan la ayuda de los no indígenas para obtener servicios y artículos básicos.

Aunque cada medio tiene excepciones, se puede apreciar cómo la mayoría de las notas analizadas no cumplen con las prácticas éticamente funcionales que se mencionaron al inicio de esta investigación. Los medios analizados abordan las problemáticas indígenas de una manera distorsionada. Asumen una visión excluyente y centran el protagonismo en los no indígenas desde una perspectiva generalizada. Estos patrones, como hemos apreciado en el análisis, controlan los abordajes de las problemáticas de los pueblos aborígenes en la prensa escrita nacional.

\section{Referencias}

González Campos, G. y Bolaños Esquivel, B. (2010). Las miradas con que vemos. San José: Vicerrectoría de Acción Social, Universidad de Costa Rica.

Foucault, M. (1991). Arqueología del saber. México: Siglo XXI.

Unesco: Sean MacBride y otros (1980). Voces Múltiples, Un Solo Mundo. México: Fondo de Cultura Económica.

Bilbeny, N. (2012). Ética del periodismo. Barcelona: Universidad de Barcelona.

\section{Otras fuentes}

Agencia Española de Cooperación Internacional para el Desarrollo-Fondo de las Naciones Unidas para la Infancia (UNICEF). (2012). "Sistematización de Buenas Prácticas desarrolladas para la promoción de estilos de vida saludables y la atención de la salud materno-infantil 
en la población indígena Ngöbe". Costa Rica. Recuperado de: http:// www.aecid.es/

Barrantes, Alberto (5 de mayo de 2015). "Estado dará cuentas sobre protección a los indígenas". $\mathrm{La} \mathrm{Na-}$ ción. Recuperado de: http://www. nacion.com/nacional/gobierno/ dara-cuentas-proteccion-indigenas_0_1485651468.html

“Crece usurpación en territorios indígenas de Buenos Aires". (18 de julio de 2004). La Nación. Recuperado de: http://www.nacion.com/nacional/ Crece-usurpacion-territorios-Buenos-Aires_0_697130447.html

La Nación. (11 de julio de 2014). Editorial "El derecho de los indígenas a la tierra". La Nación. Recuperado de: http://www.nacion.com/opinion/editorial/derecho-indigenastierra_0_1426057383.html
Rodríguez, Irene. (19 de abril de 2017). "Universidad Nacional celebró diversidad cultural en el Día del Aborigen". La Nación. Recuperado de: http://www.nacion.com/ vivir/patrimonio/UniversidadNacional-diversidad-Dia-Aborigen_0_1628637184.html

Villalobos, Marcela. (20 de marzo de 2017). "Mujeres indígenas aprenderán a instalar paneles solares". Costa Rica Hoy. Recuperado de: https://www.crhoy.com/nacionales/ mujeres-indigenas-aprenderan-ainstalar-paneles-solares/

Ugarte, Joselyne. (15 de octubre de 2016). "Indígenas bribri tendrán su propia agencia de turismo". Costa Rica Hoy. Recuperado de: https://www.crhoy. com/economia/indigenas-bribri-tendran-su-propia-agencia-de-turismo/ 
